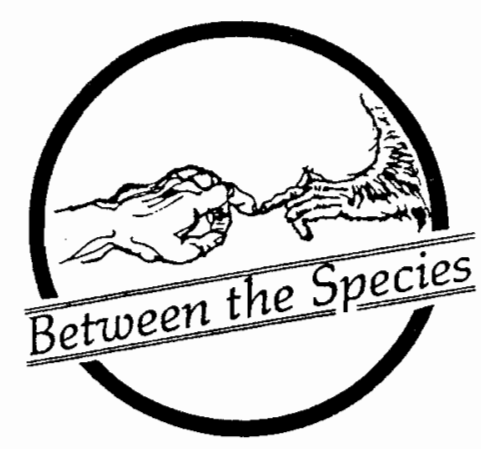

\title{
Moral Standing, The Value of Lives, and Speciesism
}

The question of who or what has moral standing, of who or what is a member of the moral community, has received wide exposure in recent years. Various answers have been extensively canvassed; and though controversy still envelops claims for the inclusion of the inanimate environment within the moral community, such claims on behalf of animals (or, at least, the "higher" animals) are now widely accepted. Morally, then, animals count. I do not myself think that we have needed a great deal of argument to establish this point; but numerous writers, obviously, have thought otherwise. In any event, no work of mine has ever denied that animals count. In order to suffer, animals do not have to be self-conscious, to have interests or beliefs or language, to have desires and desires related to their own future, to exercise self-critical control of their behaviour, or to possess rights; and I, a utilitarian, take their sufferings into account, morally. Thus, the scope of the moral community, at least so far as ("higher") animals are concerned, is not something I contest. I may disagree with some particular way of trying to show that animals possess moral standing, e.g., by ascribing them some variant of moral rights,

\author{
R.G. Frey \\ Bowling Green State University
}

Editorg'Note:
This essay by Professor Frey
and the comments following it
by Peter Singer were presented
at the Pacific Division Meeting
of the Society for the Study of
Ethies and Animals, held in San
Francisco in March of 1987.

but I have no quarrel with the general claim that they possess such standing. Indeed, my reformist position with respect to vegetarianism, vivisection, and our general use of animals in part turns upon this very fact.

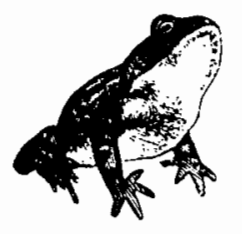

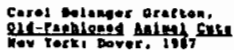

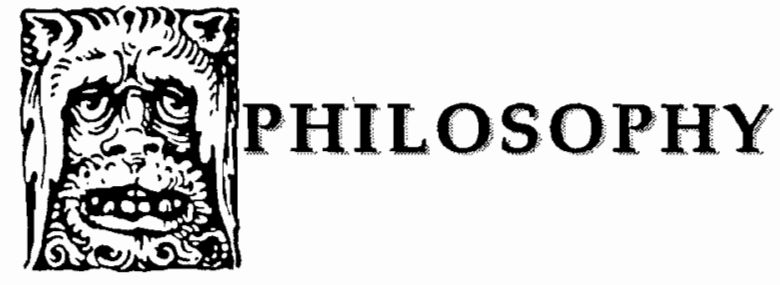


As I have indicated in my two books and numerous articles on animal issues, ${ }^{1}$ my reservations come elsewhere. Some of these doubts and criticisms I have explored and developed in a series of recent articles. ${ }^{2}$ There, I have focussed upon the comparative value of human and animal life; I have taken the notion of autonomy to be central to this issue, since the exercise of autonomy by normal adult humans is the source of an immense part of the value of their lives. Here, I want to sketch one way this concern with the comparative value of human and animal life comes to have importance and to interact with the charge of speciesism.

I.

Those who concern themselves with the moral considerability of animals may well be tempted to suppose that their work is finished, once they successfully envelop animals within the moral community. Yet, to stop there is never per se to address the issue of the value of animal life and so never to engage the position that $\mathrm{I}$, and others, hold on certain issues. Thus, I am a restricted vivisectionist, ${ }^{3}$ not because I think animals are outside the moral community but because of views I hold about the value of their lives. Again, I think it is permissible to use animal parts in human transplants, ${ }^{4}$ not because I think animals lack moral standing but because I think animal life is less valuable than human life. (As some readers may know, $I$ argue that experiments upon animals and the use of animal parts in human transplants are only permissible if one is prepared to sanction such experiments upon and the use of certain humans. I think the benefits to be derived from these practices are sometimes substantial enough to compel me to endorse the practices in the human case, unless the side-effects of any such decision offset these benefits. ${ }^{5} \mathrm{I}$ return to this matter of our use of humans below.)

I have written of views that I hold; the fact is, I think, that the vast majority of people share my view of the differing value of human and animal life. This view we might capture in the form of three propositions:

\section{Animal life has some value;}

2. Not all animal life has the same value;

3. Human life is more valuable than animal life.
Very few people today would seem to believe that animal life is without value and that, therefore, we need not trouble ourselves morally about taking it. Equally few people, however, would seem to believe that all animal life has the same value. Certainly, the lives of dogs, cats, and chimps are very widely held to be more valuable than the lives of mice, rats, and worms, and the legal protections we accord these different creatures, for example, reflect this fact. Finally, whatever value we take the lives of dogs and cats to have, most of us believe human life to be more valuable than animal life. We believe this, moreover, even as we oppose cruelty to animals and acknowledge value - in the case of some animals, considerable value - to their lives. I shall call this claim about the comparative value of human and animal life the unequal value thesis. A crucial question, obviously, is whether we who hold this thesis can defend it.

Many "animal rightists" themselves seem inclined to accept something like the unequal value thesis. With respect to the oft-cited raft example, in which one can save a man or a dog but not both, animal rightists often concede that, other things being equal, one ought to save the man. To be sure, this result only says something about our intuitions and about those in extremis; yet, what it is ordinarily taken to say about them - that we take human life to be more valuable than animal life - is not something we think in extreme circumstances only. Our intuitions about the greater value of human life seem apparent in and affect all our relations with animals, from the differences in the ways we regard, treat, and even bury humans and animals to the differences in the safeguards for their protection that we construct and the differences in penalties we exact for violation of those safeguards.

In a word, the unequal value thesis seems very much a part of the approach that most of us adopt towards animal issues. We oppose cruelty to animals as well as humans, but this does not lead us to suppose that the lives of humans and animals have the same value. Nor is there any entailment in the matter: one can perfectly consistently oppose cruelty to all sentient creatures without having to suppose that the lives of all such creatures are equally valuable.

We might note in passing that if this is right about our intuitions, then it is far from clear that it is the defender of the unequal value thesis who must assume the burden of proof in the present discussion. Our intuitions about pain and suffering are such that 
if a theorist today suggested that animal suffering did not count morally, then he would quickly find himself on the defensive. If I am right about our intuitions over the comparative value of human and animal life, why is the same not true in the case of the theorist who urges or assumes that these lives are of equal value? If, over suffering, our intuitions force the exclusion of the pains of animals to be defended, why, over the value of life, do they not force an equal value thesis to be defended? In any event, I have not left this matter of the burden of proof to chance in my other work (see also below), where I have argued for the unequal value thesis. Here, I want only to stress that our intuitions do not obviously endorse, as it were, a starting-point of equality of value in the lives of humans and animals. ${ }^{6}$ On the strength of this consideration alone, we seem justified in at least treating sceptically arguments and claims that proceed from or implicitly rely upon some initial presumption of equal value, in order to undermine the unequal value thesis from the outset.

Where pain and suffering are the central issue, most of us tend to think of the human and animal cases in the same way; thus, cruelty to a child and cruelty to a dog are wrong and wrong for the same reason. ${ }^{7}$ Pain is pain; it is an evil, and the evidence suggests that it is as much an evil for dogs as for humans. ${ }^{8}$ Furthermore, autonomy or agency (or the lack thereof) does not seem a relevant factor here, since the pains of nonautonomous creatures count as well as the pains of autonomous ones. Neither the child nor the dog is autonomous, at least in any sense that captures why autonomy is such an immensely important value; but the pains of both child and dog count and affect our judgments of rightness and wrongness with respect to what is done to them.

Where the value of life is the central issue, however, we do not tend to think of the human and animal cases alike. Here, we come down in favor of humans, as when we regularly experiment upon and kill animals in our laboratories for (typically) human benefit; and a main justification reflective people give for according humans such advantage invokes directly a difference in value between human and animal life. Autonomy or agency is now, moreover, of the utmost significance, since the exercise of autonomy by normal adult humans is one of the central ways they make possible further, important dimensions of value to their lives.
Arguably, even the extended justification of animal suffering in, say, medical research may make indirect appeal to the unequal value thesis. Though pain remains an evil, the nature and size of some benefit determine whether its infliction is justified in the particular cases. Nothing precludes this benefit from accruing to human beings, and when it does, we need an independent defence of the appeal to benefit in this kind of case. For the appeal is typically invoked in cases where those who suffer are those who benefit, as when we go to the dentist, and in the present instance human beings are the beneficiaries of animal suffering. Possibly the unequal value thesis can provide the requisite defence: what justifies the infliction of pain, if anything does, is the appeal to benefit; but what justifies use of the appeal in those cases where humans are the beneficiaries of animal suffering is, arguably, that human life is more valuable than animal life. Thus, while the unequal value thesis cannot alter the character of pain, which remains an evil, and cannot directly, independently of benefit, justify the infliction of pain, it can, the suggestion is, anchor a particular use of the appeal to benefit.

I do not have space to discuss what constitutes a benefit, the magnitude of benefit required in order to justify the infliction of pain, and some principle of proportionality that rejects even a significant benefit at a cost of immense and excruciating suffering. In general, my views on these matters favor animals, especially when further commercial products are in question but also even when much medical/scientific research is under consideration. More broadly, I think a presumption, not in favor of, but against the use of animals in medical/scientific research would be desirable. Its intended effect would be to force researchers as a matter of routine to argue in depth a case for animal use. ${ }^{9}$ Such a presumption coheres with my earlier remarks. The unequal value thesis in no way compels its adherents to deny that animal lives have value; the destruction or impairment of such lives, therefore, needs to be argued for, which a presumption against use of animals would force researchers to do.

Clearly, a presumption against use is not the same thing as a bar; I allow, therefore, that researchers can make'a case. That they must do so, that they must seek to justify the destruction or impairment of lives that have value, is the point. 
II.

How might we defend the unequal value thesis? At least the beginnings of what I take to be the most promising option in this regard can be briefly sketched.

Pain is one thing, killing is another, and what makes killing wrong - a killing could be free of pain and suffering - seems to be the fact that it consists in the destruction of something of value. That is, killing and the value of life seem straightforwardly connected, since it is difficult to understand why taking a particular life would be wrong if it had no value. If few people consider animal life to be without value, equally few, I think, consider it to have the same value as normal (adult) human life. They need not be speciesists as a result: in my view, normal (adult) human life is of a much higher quality than animal life, not because of species, but because of richness; and the value of a life is a function of its quality.

Part of the richness of our lives involves activities that we have in common with animals but there are as well whole dimensions to our lives - love, marriage, educating children, jobs, hobbies, sporting events, cultural pursuits, intellectual development and striving, etc. - that greatly expand our range of absorbing endeavors and so significantly deepen the texture of our lives. An impoverished life for us need not be one in which food or sex or liberty is absent; it can equally well be a life in which these other dimensions have not taken root or have done so only minimally. When we look back over our lives and regret that we did not make more of them, we rarely have in mind only the kinds of activities that we share with animals; rather, we think much more in terms of precisely these other dimensions of our lives that equally go to make up a rich, full life.

The lives of normal (adult) humans betray a variety and richness that the lives of rabbits do not; certainly, we do not think of ourselves as constrained to live out our lives according to some (conception of a) life deemed appropriate to our species. Other conceptions of a life for ourselves are within our reach, and we can try to understand and appreciate them and to choose among them. Some of us are artists, others educators, still others mechanics; the richness of our lives is easily enhanced through developing and molding our talents so as to enable us to live out these conceptions of the good life. Importantly, also, we are not condemned to embrace in our lifetimes only a single conception of such a life; in the sense intended, the artist can choose to become an educator and the educator a mechanic. We can embrace at different times different conceptions of how we want to live.

Choosing among conceptions of the good life and trying to live out such a conception are not so intellectualized a set of tasks that only an elite few can manage them. Some reflection upon the life one wants to live is necessary, and some reflection is required in order to organize one's life to live out such a conception; but virtually all of us manage to engage in this degree of reflection. (One of the tragic aspects of Alzheimer's disease is how it undoes a person in just this regard, once it has reached advanced stages.) Even an uneducated man can see the choice between the army and professional boxing as one that requires him to sit down and ponder what he wants to do, whether he has the talents to do it, and what his other, perhaps conflicting desires come to in strength. Even an habitual street person, if free long enough from the influence of drink or drugs to be capable of addressing himself to the choice, can see the life the Salvation Army holds out before him as different in certain respects, some appealing, others perhaps not, from his present life. Choosing how one will live one's life can often be a matter of simply focussing upon these particulars and trying to gauge one's desires with respect to them.

Now, in the case of the rabbit the point is not that the activities which enrich an adult human's life are different from those which enrich its life; it is that the scope or potentiality for enrichment is truncated or severely diminished in the rabbit's case. The quality of a life is a function of its richness, which is a function of its scope or potentiality for enrichment; the scope or potentiality for enrichment in the rabbit's case never approaches that of the human. Nothing we have ever observed about rabbits, nothing we know of them, leads us to make judgments about the variety and richness of their life in anything even remotely comparable to the judgments we make in the human case. To assume as present in the rabbit's life dimensions that supply the full variety and richness of ours, only that these dimensions are hidden from us, provides no real answer, especially when the evidence we have about their lives runs in the other direction.

Autonomy is an important part of the human case. By exercising our autonomy we can mold our lives to fit a conception of the good life that we have decided upon for ourselves; we can then try to live 
out this conception, with all the sense of achievement, self-fulfillment, and satisfaction that this can bring. Some of us pursue athletic or cultural or intellectual endeavors; some of us are good with our hands and enjoy mechanical tasks and manual labor; and all of us see a job - be it the one we have or the one we should like to have - as an important part of a full life. (This is why unemployment affects more than just our incomes.) The emphasis is upon agency: we can make ourselves into repairmen, pianists, and accountants; by exercising our autonomy, we can impose upon our lives a conception of the good life that we have for the moment embraced. We can then try to live out this conception, with the consequent sense of fulfillment and achievement that this makes possible. Even failure can be part of the picture: a woman can try to make herself into an Olympic athlete and fail; but her efforts to develop and shape her talents and to take control of and to mold her life in the appropriate ways can enrich her life. Thus, by exercising our autonomy and trying to live out some conception of how we want to live, we make possible further, important dimensions of value to our lives.

We still share certain activities with rabbits, but no mere record of those activities would come anywhere near accounting for the richness of our lives. What is missing in the rabbit's case is the same scope or potentiality for enrichment; and lives of less richness have less value.

The kind of story that would have to be told to make us think that the rabbit's life was as rich as the life of a normal (adult) human is one that either postulates in the rabbit potentialities and abilities vastly beyond what we observe and take it to have, or lapses into a rigorous scepticism. By the latter, I mean that we should have to say either that we know nothing of the rabbit's life (and so can know nothing of that life's richness and quality) or that what we know can never be construed as adequate for grounding judgments about the rabbit's quality of life. ${ }^{10}$ Such sceptical claims, particularly after Ryle and Wittgenstein on the one hand and much scientific work on the other, may strike many as misplaced, and those who have recourse to them, at least in my experience, have little difficulty in pronouncing pain and suffering, stress, loss of liberty, monotony, and a host of other things to be detrimental to an animal's quality of life. But the real puzzle is how this recourse to scepticism is supposed to make us think that a rabbit's life is as varied and rich as a human's life. If I can know nothing of the rabbit's life, presumably because I do not live that life and so cannot experience it from the inside (this whole way of putting the matter sets ill with a post-Ryle, post-Wittgenstein understanding of psychological concepts and inner processes), then how do I know that the rabbit's life is as rich as a human's life? Plainly, if I cannot know this, I must for the argument's sake assume it. But why should I do this? Nothing I observe and experience leads me to assume it; all the evidence I have about rabbits and humans seems to run entirely in the opposite direction. So, why make this assumption? Most especially, why assume animal lives are as rich as human lives, when we do not even assume, or so I suggest below, that all human lives have the same richness?

\section{III.}

I have taken autonomy to be or to imply agency, and I have elsewhere considered two ways animal rightists might try to move on this issue. On the one hand, I have in my paper "The Significance of Agency and Marginal Cases" considered attempts to work animals into the class of the autonomous by appeal to (i) some distinction between potential and actual autonomy, (ii) some notion of impaired autonomy, (iii) some attempt to loosen the requirements for possessing one or more of the components of agency, and (iv) some notion of proxy agency. On the other hand, both in that paper and in "Autonomy and the Value of Animal Life," I have considered the attempt, notably by Tom Regan, ${ }^{11}$ to sever autonomy from agency altogether. Both paths I have argued against and tried to show why they will not substantiate the claims that animal lives are as rich as human lives and that animal lives have roughly the same value as human lives. In Regan's case in particular, I have been concerned to show that any sense of autonomy that severs the concept from agency has been drained of virtually all the significance for the value of a life that we take autonomy to have.

Agency matters to the value of a life, and animals are not agents. Thus, we require some argument to show that their lack of agency notwithstanding, animals have lives of roughly equal richness and value to the lives of normal (adult) humans. The view that they are members of the moral community will not supply it, the demand is compatible with acknowledging that not all life has the same value; and as we shall see, the argument from the value of the lives of defective humans will not supply it. Any 
assumption that they have lives of equal richness and value to ours seems to run up against, quite apart from the evidence we take ourselves to have about the lives of animals, the fact that, as we shall see, not all human lives have the same richness and value.

Most importantly, it will not do to claim that the rabbit's life is as valuable as the normal (adult) human's life because it is the only life each has. This claim does not as yet say that the rabbit's life has any particular value. If the rabbit and man are dead, they have no life which they can carry on living, at some quality or other; but this per se does not show that the lives of the man and the rabbit have a particular value as such, let alone that they have the same value. Put differently, both creatures must be alive in order to have a quality of life, but nothing at all in this shows that they have the same richness and quality of life and, therefore, value of life. ${ }^{12}$ I am not disputing that animals can have $a$ quality of life and that their lives, as a result, can have value; I am disputing that the richness, quality, and value of their lives is that of normal (adult) humans.

\section{IV.}

Not all members of the moral community have lives of equal value. Human life is more valuable than animal life. That is our intuition, and as I have assumed, we must defend it. How we defend it is, however, a vitally important affair. For I take the charge of speciesism - the attempt to justify either different treatment or the attribution of a different value of life by appeal to species membership - very seriously. In my view, if a defence of the unequal value thesis is open to that charge, then it is no defence at all.

As a result, one's options for grounding the unequal value thesis become limited; no ground will suffice that appeals, either in whole or in part, to species membership. Certainly, some ways of trying to differentiate the value of human from animal life in the past seem pretty clearly to be speciesist. But not all ways are; the important option set out above - one that construes the value of a life as a function of its quality, its quality as a function of its richness, and its richness as a function of its capacity of enrichment - does not use species membership to determine the value of lives. Indeed, it quite explicitly allows for the possibility that some animal life may be more valuable than some human life.

To see this, we have only to realize that the claim that not all members of the moral community have lives of equal value encompasses not only animals but also some humans. Some human lives have less value than others. An infant born without a brain, or any very severely handicapped infant, seems a case in point, as does an elderly person fully in the grip of Alzheimer's disease or some highly degenerative brain, nervous, or physiological disorder. In other words, I think we are compelled to admit that some human life is of a much lower quality and so value than normal (adult) human life. (This is true as well of infants generally, though readers may think in their cases, unlike the cases of seriously defective infants and adults, some argument from potentiality may be adduced to place them in a separate category. The fact remains, however, that the lives of normal (adult) humans betray a variety and richness that the lives of animals, defective humans, and infants do not.)

Accordingly, we must understand the unequal value thesis to claim that normal (adult) human life is more valuable than animal life. If we justify this claim by appeal to the quality and richness of normal (adult) human life and if we at the same time acknowledge that some human life is of a much lower quality and value than normal (adulr) human life, then it seems quite clear that we are not using species membership to determine the value of a life.

Moreover, because some human lives fall drastically below the quality of life of normal (adult) human life, we must face the prospect that the lives of some perfectly healthy animals have a higher quality and greater value than the lives of some humans. And we must face this prospect, with all the implications it may have for the use of these unfortunate humans by others, at least if we continue to justify the use of animals in medical/scientific research by appeal to the lower quality and value of their lives. ${ }^{13}$

What justifies the medical/scientific use of perfectly healthy rabbits instead of humans with a low quality of life? If, for example, experiments on retinas are suggested, why use rabbits or chimps instead of defective humans with otherwise excellent retinas? I know of nothing that cedes human life of any quality, however low, greater value than animal life of any quality, however high. If, therefore, we are going to justify medical/scientific uses of animals by appeal to the value of their lives, we open up directly the possibility of our having to envisage the use of humans of a lower quality of life in preference to animals of a higher quality of life. It is important to 
bear in mind as well that other factors then come under consideration, such as (i) the nature and size of benefit to be achieved, (ii) the side-effects that any decision to use humans in preference to animals may evoke, (iii) the degree to which education and explanation can dissipate any such negative sideeffects, and (iv) the projected reliability of animal results for the human case (as opposed to the projected reliability of human results for the human case). All these things may, in the particular case, work in favor of the use of humans.

The point, of course, is not that we must use humans; it is that we cannot invariably use animals in preference to humans, if appeal to the quality and value of lives is the ground we give for using animals. The only way we could justifiably do this is if we could cite something that always, no matter what, cedes human life greater value than animal life. I know of no such thing.

Always in the background, of course, are the benefits that medical/scientific research confers: if we desire to continue to obtain these benefits, are we prepared to pay the price of the use of defective humans? The answer, I think, must be positive, at least until the time comes when we no longer have to use either humans or animals for research purposes. Obviously, this deliberate use of some of the weakest members of our society is distasteful to contemplate and is not something, in the absence of substantial benefit, that we could condone; yet, we presently condone the use of perfectly heal thy animals on an absolutely massive scale, and benefit is the justification we employ.

I remain a vivisectionist, therefore, because of the benefits medical/scientific research can bestow. Support for vivisection, however, exacts a cost: it forces us to envisage the use of defective humans in such research. Paradoxically, then, to the extent that one cannot bring oneself to envisage and consent to their use, to that extent, in my view, the case for anti-vivisectionism becomes stronger.

\section{V.}

The fact that not even all human life has the same value explains why some argument from marginal cases, one of the most common arguments in support of an equal value thesis, comes unstuck. Such an argument would only be possible if human life of a much lower quality were ceded equal value with normal (adult) human life. In that case, the same concession could be requested for animal life, and an argument from marginal or defective humans could get underway. On the account of the value of a life set out above, however, the initial concession is not made; it is not true that defective human life has the same quality and value as normal (adult) human life. Nor is this result unfamiliar to us today; it is widely employed in much theoretical and practical work in medical ethics.

This fate of the argument from marginal cases matters; for unless one adopts a reverence for life principle (a possibility that I considered and rejected in Rights, Killing, and Suffering ${ }^{14}$ or adopts some form of holistic ethic, the supposed equal value of human and animal life, if it is not to be merely assumed, is often made to turn upon some variant of the argument from marginal cases.

As for an holistic account of value, wherein the value of the parts of an eco-system turns upon the value of the whole, this is much too large an issue for me to address here. Suffice it to say that I have elsewhere expressed doubts about any such account. ${ }^{15}$ I have no very clear idea of exactly how one sets about uncovering the value of an entire ecosystem, in order to arrive at some view of the value of humans and animals within it, or how one knows one has ascertained that value correctly. There seems no touchstone of error in any such uncovering; that is, there seems no clear way to contest one's claim that some eco-system in some particular state has whatever value one says it has.

This leaves the argument from marginal cases to try to force the admission of the equal value of human and animal life. Tom Regan has long relied upon this argument, and though I have given my objections to his position in another place, ${ }^{16}$ a word on his use of the argument may help in part to clarify why I reject it.

In a recent article Regan wonders what could be the basis for the view that human life is more valuable than animal life and moves at once to invoke the argument from marginal cases to dispel any such possibility:

What could be the basis of our having more inherent value than animals? Their lack of reason, or autonomy, or intellect? Only if we are willing to make the same judgment in the case of humans who are similarly deficient. But it is not true that some humans - the retarded child, for example, or the mentally deranged have less inherent value than you or I.17 
Regan provides no argument for this claim (and, for that matter, no analysis of "inherent value"), but it seems at least to involve, if not to depend upon, our agreeing that human life of any quality, however low, has the same value as normal (adult) human life. I can see no reason whatever to accept this. Some human lives are so very deficient in quality that we would not wish those lives upon anyone, and there are few lengths to which we would not go in order to avoid such lives for ourselves and our loved ones. I can see little point in pretending that lives which we would do everything we could to avoid are of equal value to those normal (adult) human lives that we are presently living.

Of course, it is always possible to draw up, say, six different senses in which lives may be said to be valuable and to try to make out that deficient human life is as valuable as normal (adult) human life in four or five of them. I suspect that most of us, however, would see such an exercise as just that. For in however many senses human lives may be said to be valuable, the fact remains that we would do everything we could to avoid a life of severe derangement or mental enfeebleness or physical paralysis. It is hard to believe, as a result, that normal (adult) humans would consider such a life to be as valuable as their present life or to be a life - think of a life in the advanced stages of AIDS - that they would even remotely regard as a life as desirable to live as their present one.

So far as I can see, the quality of some lives can plummet so disastrously that those lives can cease to have much value at all, can cease to be lives, that is, that are any longer worth living. I acknowledge the difficulty in determining in many cases when a life is no longer worth living; in other cases, however, such as an elderly person completely undone by Alzheimer's disease or an infant born with no or only half a brain, the matter seems far less problematic.

VI.

Is an involved defence of the unequal value thesis, however, really necessary? Is there not a much more direct and uncomplicated defence readily to hand? I have space for only a few words on several possibilities in this regard.

The defence of the unequal value thesis that I have begun to sketch, whether in its positive or negative aspect, does not make reference to religion; yet, it is true that certain religious beliefs seem to favor the thesis. The doctrine of the sanctity of life has normally been held with respect to human life alone; the belief in human dominion over the rest of creation has traditionally been held to set humans apart; and the belief that humans but not animals are possessed of an immortal soul seems plainly to allude to a further dimension of significance to human life. I am not myself religious, however, and I do not adopt a religious approach to questions about the value of lives. Any such approach would seem to tie one's defence of the unequal value thesis to the adequacy of one's theological views, something which a non-religious person can scarcely endorse. I seek a defence of the unequal value thesis, whatever the status of God's existence or the adequacy of this or that religion or religious doctrine. I do not prejudge the issue of whether a religious person can accept a quality-of-life defence of the sort I have favored; my point is simply that that defence does not rely upon theological premisses.

It may be asked, however, why we need anything quite so sophisticated as a defence of the unequal value thesis at all. Why can we not just express a preference for our own kind and be done with the matter? After all, when a father gives a kidney to save his daughter's life, we perfectly well understand why he did not choose to give the kidney to a stranger in preference to his daughter. This "natural bias" we do not condemn and do not take to point to a moral defect in the father. Why, therefore, is not something similar possible in the case of our interaction with animals? Why, that is, can we not appeal to a natural bias in favor of members of our own species? There are a number of things that can be said in response, only several of which I shall notice here.

There is the problem, if one takes the charge of speciesism seriously, of how to articulate this bias in favor of members of our species in such a way as to avoid that charge. Then there is the problem of how to articulate this preference for our own kind in such a way as to exclude interpretations of "our own kind" that express preferences for one's own race, gender, or religion. Otherwise, one is going to let such preferences do considerable work in one's moral decision-making. I do not wish to foreclose all possibilities in these two cases, however; it may well be that a preference for our own kind can be articulated in a way that avoids these and some other problems. 
Even so, I believe that there is another and deeper level of problem that this preference for our own kind encounters. On the one hand, we can understand the preference to express a bond we feel with members of our own species over and above the bond that we (or most of us) feel with ("higher") animals. Such a bond, if it exists, poses no direct problem, if its existence is being used to explain, for example, instances of behavior where we obviously exhibit sympathy for human beings. (We must be careful not to under-value the sympathy most people exhibit towards animals, especially domesticated ones.) On the other hand, we can understand this preference for our own kind to express the claim that we stand in a special moral relationship to members of our own species. This claim does pose a problem, since, if we systematically favor humans over animals on the basis of it, it does considerable moral work, work, obviously, that would not be done if the claim were rejected. I have elsewhere commented on this claim;18 a word on one facet of it must suffice here.

I cannot see that species membership is a ground for holding that we stand in a special moral relationship to our fellow humans. The father obviously stands in such a relationship to his daughter, and his decision to marry and to have children is how he comes to have or to stand in that relationship. But how, through merely being born, does one come to stand in a special moral relationship to humans generally? Typically, I can step in and out of special moral relationships; in the case of species membership, that is not true. In that case, so long as I live, nothing can change my relationship to others, so long as they live. If this were true, my morality would to an extent no longer express my view of myself at large in a world filled with other people but would be something foisted upon me simply through being born.

Since we do not choose our species membership, a special moral relationship I am supposed to stand in to humans generally would lie outside my control; whereas it is precisely the voluntary nature of such relationships that seems most central to their character. And it is precisely because of this voluntary nature, of, as it were, our ability to take on and shed such relationships, that these relationships can be read as expressing my view of myself at large in a world filled with other people.

We often do stand in special moral relationships to others; but mere species membership would have us stand in such a relationship to all others. There is something too sweeping about this, as if birth alone can give the rest of human creation a moral hold over me. In a real sense, such a view would sever me from my morality; for my morality would no longer consist in expressions of how I see myself interacting with others and how I choose to interact with them. My own choices and decisions have no effect upon species membership and so on a moral relationship that I am supposed to stand in to each and every living, human being. Such a view is at odds not only with how we typically understand special moral relationships but also with how we typically understand our relationship to our own morality.

\section{VII.}

It may well be tempting, I suppose, to try to develop another sense of "speciesism" and to hold that a position such as mine is speciesist in that sense. I have space here for only a few comments on one such sense.

If to be a direct speciesist is to discriminate among the value of lives solely on the basis of species membership, as it is, for example, for Peter Singer, than I am not, as I have tried to show, a direct speciesist. But am I not, it might be suggested, an indirect speciesist, in that, in order to determine the quality and value of a life, I use human-centred criteria as if they were appropriate for assessing the quality and value of all life? Thus, for instance, when I emphasize cultural and artistic endeavors, when I emphasize autonomy and mental development and achievement, when I emphasize making choices, directing one's life, and selecting and living out conceptions of the good life, the effect is to widen the gulf between animals and humans by using human-centred criteria for assessing the quality and value of a life as if they were appropriate to appreciating the quality and value of animal life. And this will not do; for it amounts to trying to judge animals and animal lives by human standards. What one should do, presumably, is to judge the quality and value of animal life by criteria appropriate to each separate species of animals.

I stress again that the argument of this paper is not about whether rabbits have lives of value (I think that they do) but rather about whether they have lives of equal value to normal (adult) human life. It is unclear to me how the charge of indirect speciesism addresses this argument.

We must distinguish this charge of an indirect 
speciesism from the claim, noted earlier, that we can know nothing of animal lives and so nothing about their quality and value; indeed, the two claims may conflict. The point behind the speciesism charge is that I am not using criteria appropriate to a species of animal for assessing its quality of life, which presumably means that there are appropriate criteria available for selection. Knowledge of appropriate criteria seems to require that we know something of an animal's life, in order to make the judgment of appropriateness. Yet, the whole point behind the lack of knowledge claim is that we can know nothing of an animal's life, nothing of how it experiences the world, nothing, in essence, about how well or how badly its life is going. It would seem, therefore, as if the two views can conflict.

The crucial thing here about both claims, however, is this: both are advanced against my defence of the unequal value thesis and on behalf of the equality of value of human and animal life without it being in any wise clear how they show this equality.

The ignorance claim would seem to have it that, because we can know nothing of the animal case, we must assume that animal and human life have the same value. But why should we fall in with this assumption? The ignorance claim would have us start from the idea, presumably, that all life, irrespective of its level of development and complexity, has the same value; but why should be start from that particular idea? Surely there must be some reason for thinking all life whatever has the same value. It is this reason that needs to be stated and assessed.

The indirect speciesist claim would seem to have it that, were we only to select criteria for assessing the quality and value of life appropriate to animals' species, we must agree that animal and human life are of equal value. The temptation is to inquire after what these criteria might be in rabbits, but any such concern must be firmly understood in the light of the earlier discussion of the richness of our lives. What the unequal value thesis represents is our quest to gain some understanding of (i) the capacities of animals and humans, (ii) the differences among these various capacities, (iii) the complexity of lives, (iv) the role of agency in this complexity, and (v) the way agency enables humans to add further dimensions of value to their lives. The richness of our lives encompasses these multi-faceted aspects of our being and is a function of them. The point is not that a rabbit may not have a keener sense of smell than we do and may not derive intense, pleasurable sensations through that sense of smell; it is that we have to believe that something like this, augmented, perhaps, by other things we might say in the rabbit's case of like kind, suffices to make the rabbit's life as rich and as full as ours. If one thinks of our various capacities and of the different levels on which they operate, physical, mental, emotional, imaginative, then pointing out that rabbits can have as pleasurable sensations as we do in certain regards does not meet the point.

When we say of a woman that she has "tasted life to the full," we do not make a point about (or solely about) pleasurable sensations; we refer to the different dimensions of our being and to the woman's attempt to develop these in herself and to actualize them in the course of her daily life. And an important aspect in all this is what agency means to the woman: in the sense intended, she is not condemned to live the life that all of her ancestors have lived; she can mold and shape her life to "fit" her own conception of how she should live, thereby enabling her to add further dimensions of value to her life. It is this diversity and complexity in us that needs to be made good in the rabbit's case and that no mere catalogue of its pleasures through the sense of smell seems likely to accomplish.

Again, it is not that the rabbit cannot do things that we are unable to do and not that it has capacities which we lack; what has to be shown is how this sort of thing, given how rabbits behave and live out their days, so enriches their lives that the quality and value of them approach those of humans. And what is one going to say in the rabbit's case that makes good the role agency plays in ours? The absence of agency from a human life is a terrible thing; it deeply impoverishes a life and forestalls completely one's making one's life into the life one wants to live. Yet, this must be the natural condition of rabbits. It is this gulf that agency creates, the gulf between living out the life appropriate to one's species and living out a life one has chosen for oneself and has molded and shaped accordingly, that is one of the things that it is difficult to understand what rabbits can do to overcome. 


\section{VIII.}

In sum, I think the unequal value thesis is defensible and can be defended even as its adherent takes seriously the charge of speciesism. And it is the unequal value thesis that figures centrally in the justification of our use of animals in medical and scientific research. If as I have done here, we assume that the thesis must be defended, then the character of that defence, I think, requires that if we are to continue to use animals for research purposes, then we must begin to envisage the use of some humans for those same purposes. The cost of holding the unequal value thesis, and most of us, I suggest, do hold it, is to realize that, upon a qualityof-life defence of it, it encompasses the lives of some humans as well as animals. I cannot at the moment see that any other defence of it both meets the charge of speciesism and yet does indeed amount to a defence. 19

\section{$\underline{\text { Notes }}$}

1See especially my books Interests and Rights: The Case Against Animals (Oxford: Clarendon Press, 1980) and Rights, Killing, and Suffering (Oxford: Basil Blackwell, 1983). These give a reasonably full listing of my articles relevant to the subject of this paper, when taken together with those articles mentioned below.

2"Autonomy and The Value of Animal Life," The Monis (1986); "The Significance of Agency and Marginal Cases," Philosophica (1986); "Autonomy and Conceptions of the Good Life," in L. W. Sumner, T. Artig, D. Callen (eds.), Values and Moral Standing (Bowling Green Studies in Applied Philosophy, 1986); and "Animal Parts, Human Wholes: On the Use of Animals as a Source of Organs for Human Transplants," in J. Humber, R. Almeder (eds.), Biomedical Revieus 1987 (New Jersey: Humana Press, 1988).

${ }^{3}$ See my "Vivisection, Medicine, and Morals," Journal of Medical Ethics (1983), and Rights, Killing, and Suffering, op. cit., chpt. 12.

${ }^{4}$ See "Animal Parts, Human Wholes," op. cit.

${ }^{5}$ For a brief discussion of these side-effects, see my "Vivisection, Medicine, and Morals," op. cit.

${ }^{6}$ One might want to advance some vast generality here, of the order, for example, that all living things, just because and to the extent that they are living, have value and, perhaps, even equal value; but this generality will need argument in its support. 1 have heard such a generality advanced often in discussion, almost always, it eventually turned out, as a fundamental assumption about value; but $I$ have not come across any good reason to grant such an assumption. Besides, most of us are going to need convincing that the lives of "lower" animals, such as agricultural pests, are as valuable as human lives. This whole way of talking, however, is alien to the discussion of the value of a life I advance below, in which richness and quality of life figure prominently.

7 This is not to say, of course, that there may not be ways in which normal (adult) humans can suffer that animals do not.
${ }^{8}$ Suffering is a wider notion than pain; but 1 drop the distinction here, since it is not relevant to what follows.

${ }^{9}$ In Britain, such a presumption increasingly receives support among the public, scientific bodies, and government, where the use of animals in medical/scientific research is on the whole already subject to more severe examination than in the United States. And the matter is under continuous review. 1 am at present part of a working party in the Institute of Medical Ethics in London that is examining the ethics of our use of animals in medical research. The members come from government, industry, the medical establishment, academia, religious organizations, and animal welfare societies, and our aim is to produce a report that will assist and perhaps even direct discussion on all levels about our present, simply massive use of animals in medical research.

${ }^{10}$ Something along these sceptical lines has been suggested to me by S. F. Sapontzis, a line of argument that doubtless his book Morals, Reason, and Animals (Philadelphia: Temple University Press, 1987) will pursue. (I have only now, May, 1988, received Sapontzis' book for review.)

11Tom Regan, The Case for Animal Rights (Berkeley, University of California Press, 1983).

${ }^{12}$ For a discussion of this point, see Rights, Killing, and Suffering, op. cit., p. 110.

13I discuss this matter of our use of humans, in the context of a discussion of xenograph, in some detail in "Animal Parts, Human Wholes," op. cit. See also my "Vivisection, Medicine, and Morals," op cit., and Rights, Killing, and Suffering, op. cit., chpt. 12.

${ }^{14}$ Op. cit., chpt. 12.

${ }^{15}$ See Rights, Killing, and Suffering, op. cit., chpt. 14. This discussion is preliminary only and does not fully address a workedout, holistic theory, if there be such.

${ }^{16}$ See "Autonomy and The Value of Animal Life," op. cit.

17Tom Regan, "The Case for Animal Rights," in Peter Singer (ed.), In Defence of Animals (Oxford: Basil Blackwell, 1985), p. 23 This article mirrors some central claims of Regan's book of the same name.

${ }^{18}$ See "Animal Parts, Human Wholes," op cit.

${ }^{19}$ An earlier version of this paper was read in 1986 as my contribution to a debate with Stephen R. L. Clark, in a Wolfson College, Oxford, debate series on Animal Rights and Wrongs. It was especially pleasing to be able to join my old friend and colleague in starting off the series.

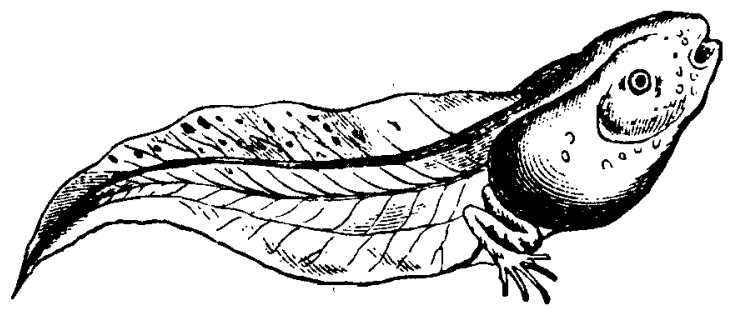

in Harter, Arimals: 1419

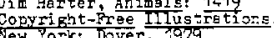

